\title{
Tropane alkaloids from a Brazilian bark traded as "Catuaba" *
}

\author{
Sabine GlasI" ${ }^{\# 1}$, Armin Presser², Ingrid Werner', Ernst Haslinger ${ }^{2}$, \\ Johann Jurenitsch ${ }^{1}$ \\ ${ }^{1}$ Institute of Pharmacognosy, University of Vienna, PharmaCenter Vienna, \\ Althanstrasse 14, A-1090 Vienna, Austria. \\ ${ }^{2}$ Institute of Pharmaceutical Chemistry, Karl Franzens University, \\ Universitätsplatz 1, A-8010 Graz, Austria \\ \# Author for correspondence and reprint requests

\begin{abstract}
Dichloromethane extracts of a Brazilian bark assigned as Anemopaegma mirandum contained four tropane alkaloids. MS-, UV-, IR-, ${ }^{1} \mathrm{H}$ NMR-data and specific optical rotation allowed the identification of catuabin $\mathrm{C}$ and its 7-exo-hydroxy20-methyl-derivative. As no alkaloids are described for Anemopaegma these results indicate heterogeneity for the investigated drug and require a further review.
\end{abstract}

\section{Keywords}

Catuaba, tropane alkaloids

\section{Introduction}

The Brazilian bark Catuaba is known as tonic, stimulant and aphrodisiac. Its long tradition in folk medicine and the increasing popularity in Europe raise the question concerning the active compounds. One Brazilian product assigned as Anemopaegma mirandum (Bignoniaceae) was screened for characteristic constituents [1]. A positive reaction with Dragendorff reagent indicated alkaloids [2], four of them were isolated, two of the isolated alkaloids were structurally elucidated by HPLC-UV, 1D and 2D-NMR, MS and IR [3].

\footnotetext{
- Presented at the $50^{\text {th }}$ Annual Congress of the Society for Medicinal Plant Research, Barcelona, Sept. 8-12, 2002: Glasl S, Kletter Ch, Presser A, Narantuya S, Haslinger E, Jurenitsch J, Stifter K, Identification problems of various Catuaba samples traded in Brazil and Europe. Book of Abstracts, Revista de Fitoterapia 2002; 2 (Suppl 1): B212.
} 


\section{Experimental}

\section{Plant material}

$50 \mathrm{~g}$ bark specified as "Catuaba - Anemopaegma mirandum, Casca; Lote 0227; MS 984.201-2, Fab 03/97" were provided by the Brazilian company As Ervas Curam. Before extraction the drug was powdered.

\section{Column chromatography}

Stationary phase: silica gel 60 Merck; mobile phase: dichloromethanemethanol mixtures with increasing polarity containing $20 \mu$ l concentrated ammonia per $200 \mathrm{ml}$. Volume per polarity step: $500 \mathrm{ml}$.

\section{HPLC}

Analyses were performed on a Merck Hitachi liquid chromatograph consisting of a Rheodyne injection unit, a L-7100 pump, a L-7450 diode array detector (monitoring wavelength: $270 \mathrm{~nm}$ ) and a D-7000 interface. Computations were performed using the Merck D-7000 HSM software. Stationary phase: LiChrospher ${ }^{\circledR} 100-R P 8$ $5 \mu \mathrm{m}(4 \times 250 \mathrm{~mm}$ ); mobile phase: methanol-water, start from $20 \%$ up to $80 \%$ methanol in 90 minutes, rate: $0,6 \% / \mathrm{min}$, flow: $1 \mathrm{ml} / \mathrm{min}$; UV spectra were recorded on-line in methanol-water by diode array detection during the HPLC runs.

IR

For IR spectra a solution of the compounds in dichloromethane was dropped on a silicon plate (13×1 mm, polished optically, Korth Kristalle $\mathrm{GmbH}$, Altenholz) leaving a slight film. Spectra were recorded with a Perkin Elmer System 2000GC IR (software Spectrum for Windows 1.30); resolution: $4 \mathrm{~cm}^{-1}$; J-stop resolution: 7.77 $\mathrm{cm}^{-1}$; apodization: strong; gain: 1; OPD velocity: $2 \mathrm{~cm} / \mathrm{s}$; interferogram: bi-directional double sided; phase correction: self 64 ; number of scans: 1 ; scan range: $5200-370$ $\mathrm{cm}^{-1}$; interval: $1.0 \mathrm{~cm}^{-1}$.

\section{NMR}

NMR-spectra were recorded on a Varian Unity Inova 400 NMR spectrometer at 297 K. Sample tubes: $5 \mathrm{~mm}$ diameter (Kontes Glass Company, The Gerresheimer Group, Düsseldorf). Dual probe head with shielded z-gradients or broadband probe $\left(400 \mathrm{MHz}\right.$ ). Solvent: acetone- $d_{6}$. Internal standard: TMS. HMBC experiments were 
optimized for a long-range coupling constant of $8 \mathrm{~Hz}$. Before NOE experiments were performed, dissolved oxygen was removed by bubbling Ar through the solution. Assignments marked with an asterisk are interchangeable.

MS

El- and Cl-MS data were recorded on a Shimadzu QP-1000 EX MSPAC 200 with direct inlet and two possible ionisation modi. El-mode: ion source: $250^{\circ} \mathrm{C}, 70 \mathrm{eV}$; vacuum: $4 \times 10^{-6}$ torr; scan: $40-500 / 2 s$; heating rate of sample vial: $80^{\circ} \mathrm{C} / \mathrm{min}$. $\mathrm{Cl}$ mode: ion source: $180^{\circ} \mathrm{C}, 200 \mathrm{eV}$; reactant gas: ammonia 2.6 (compound 1), isobutane 3.5 (compound 2), pre-pressure: 2 bar; vacuum: $5 \times 10^{-5}$ torr; scan: 40 $500 / 2 \mathrm{~s}$; heating rate of sample vial: $80^{\circ} \mathrm{C} / \mathrm{min}$.

\section{Optical rotation}

The substances were diluted in ethanol and measured with a Perkin Elmer Polarimeter 341 and photomultiplier $1 \mathrm{P} 28 \mathrm{~A}$ at $20^{\circ} \mathrm{C}$.

Compound 1 (7-exo-hydroxy-20-methyl-catuabin C): Rt-HPLC: 42min. UV $\lambda_{\max }$ (45\% MeOH): 270nm. $[\alpha]_{D}^{20}+6.5(c 0.092 \mathrm{EtOH})$. IR $v_{\max } \mathrm{cm}^{-1}: 2929(\mathrm{~s}, \mathrm{CH}), 2856$ $\left(w, \mathrm{~N}-\mathrm{CH}_{3}\right), 1702$ (s, arlyester), $1531(w, \mathrm{~N}-\mathrm{H}), 1467(w), 1413(s, \mathrm{O}-\mathrm{H}), 1320(\mathrm{~m})$, 1250 (s, C-O), 1109 (s, C-O), 1041 (w). Molecular formula: $\mathrm{C}_{20} \mathrm{H}_{25} \mathrm{~N}_{3} \mathrm{O}_{5}$. El-MS m/z (\% rel. int.): $387[\mathrm{M}]^{+}(0.5), 369[\mathrm{M}-\mathrm{OH}]^{+}(1.2), 357\left[\mathrm{M}-2 \mathrm{CH}_{3}\right]^{+}(0.9), 263\left[\mathrm{M}-\left(\mathrm{N}^{-C_{3}-}\right.\right.$

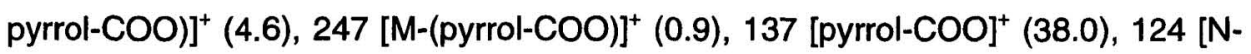

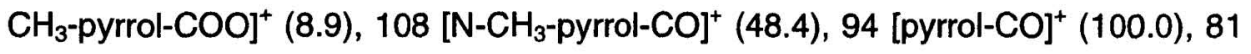
[N-CH $_{3}$-pyrrol] ${ }^{+}$(14.8). Cl-MS (ammonia) $\mathrm{m} / \mathrm{z}$ (\% rel. int.): $388[\mathrm{M}+\mathrm{H}]^{+}(100.0)$. ${ }^{1} \mathrm{H}$ NMR (400 MHz, acetone- $d_{6}$ ): 3.09-3.11 (m, H-1), 5.21 ( $\mathrm{br}, J=5.2 \mathrm{~Hz}, \mathrm{H}-3$ ), 3.293.31 (m, H-5), 5.75 (d, J=6.1 Hz, H-6), 4.72 (t br, $J=6.7 \mathrm{~Hz}, \mathrm{H}-7$ ), $2.62\left(\mathrm{~s}, \mathrm{CH}_{3}-8\right.$ ), $3.93^{\star}\left(\mathrm{s}, \mathrm{CH}_{3}-14\right), 3.94^{\star}$ (s, $\left.\mathrm{CH}_{3}-20\right)$.

Compound 2 (catuabin C): Rt-HPLC: $46 \mathrm{~min}$. UV $\lambda_{\max }(48 \% \mathrm{MeOH}): 270 \mathrm{~nm}$. $[\alpha]_{D}^{20}-28.5(c 0.047 \mathrm{EtOH}) . \mathrm{IR} v_{\max } \mathrm{cm}^{-1}: 2928(s, \mathrm{CH}), 2855\left(w, \mathrm{~N}-\mathrm{CH}_{3}\right), 1701$ (s, arlyester), $1556(w), 1531(w, N-H), 1457(w), 1412(s, \mathrm{O}-\mathrm{H}), 1320(m), 1247(s, \mathrm{C}-$ O), $1168(w), 1109$ (s, C-O), $1082(w), 1056(w), 1039(w), 1015(w)$. Molecular formula: $\mathrm{C}_{19} \mathrm{H}_{23} \mathrm{~N}_{3} \mathrm{O}_{4}$. El-MS m/z (\% rel. int.): 357 [M] (13.0), 233 [M-(N-CH- pyrrol- 
$\mathrm{COO})]^{+}$(23.4), $232(25.1), 138(8.9), 124$ [N-CH $_{3}-\mathrm{pyrrol}^{-\mathrm{COO}]^{+}}(2.5), 123$ [M-(N$\mathrm{CH}_{3}$-pyrrol-COO)-(pyrrol-COO)] $]^{+}$(5.3), 122 (32.2), 110 [pyrrol-COO] $^{+}$(3.7), 108 [N-

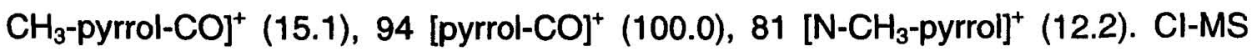
(iso-butane) $\mathrm{m} / \mathrm{z}$ (\% rel. int.): $358[\mathrm{M}+\mathrm{H}]^{+}$(100.0), 333 (8.3), 287 (1.9), 269 (5.6), 253 (9.0), 237 (7.8), 233 (8.9), 219 (10.8). ' $\mathrm{H}$ NMR (400 MHz, acetone- $d_{6}$ ): 3.313.35 (m, H-1), 5.17 (t, J=5.1 Hz, H-3), 3.25 (s br, H-5), 5.77 (dd, J=7.5, 3.1 Hz, H6), 2.20-2.27 ( $\mathrm{m}, \mathrm{H}-7_{\text {exo }}$ ), 2.68 (dd, $J=13.8,7.5 \mathrm{~Hz}, \mathrm{H}-7_{\text {endo }}$ ), 2.53 (s, $\mathrm{CH}_{3}-8$ ), 3.94 (s, $\mathrm{CH}_{3}-14$ ), 10.91 (s br, H-20).

Compound 3: Rt-HPLC: $22 \min$. UV $\lambda_{\max }(33 \% \mathrm{MeOH}): 270 \mathrm{~nm}$. El-MS m/z (\% rel. int.): $280[\mathrm{M}]^{+}$(3.9), 220 (7.0), $156\left[\mathrm{M}-\left(\mathrm{N}-\mathrm{CH}_{3}-\text { pyrrol-COO) }\right]^{+}\right.$(7.1), $108\left[{\mathrm{~N}-\mathrm{CH}_{3}}^{-}\right.$ pyrrol-CO] $^{+}$(20.4), 94 [pyrrol-CO] $^{+}(100.0)$.

Compound 4: Rt-HPLC: $35 \mathrm{~min}$. UV $\lambda_{\max }(41 \% \mathrm{MeOH}): 270 \mathrm{~nm}$. El-MS m/z (\% rel. int.): $264\left[\mathrm{M}^{+}\right.$(14.9), $249\left[\mathrm{M}-\mathrm{CH}_{3}\right]^{+}$(11.9), 220 (4.3), 140 [M-(N-CH- pyrrol$\left.\mathrm{COO}^{+}\right]^{+}(25.4), 137$ (9.2), 122 (5.2), 113 (12.7), 110 [pyrrol-COO] $^{+}(4.9), 108$ [N$\mathrm{CH}_{3}$-pyrrol-CO] ${ }^{+}$(17.3), 94 [pyrrol-CO] $^{+}(100.0), 81\left[{\mathrm{~N}-\mathrm{CH}_{3}-\text { pyrrol] }}^{+}(5.2)\right.$.

\section{Results}

$50 \mathrm{~g}$ of the powdered drug were moistened with concentrated ammonia for 15 minutes and extracted four times with $70 \mathrm{ml}$ dichloromethane. The unified dichloromethane fractions $(280 \mathrm{ml})$ were extracted five times with the same volume of $2 \mathrm{~N}$ $\mathrm{HCl}$. Subsequently the unified aqueous layers were adjusted to $\mathrm{pH} 9$ with ammonia and extracted six times with dichloromethane yielding crystals of an alkaloid mixture (44mg) after evaporation. CC on silica gel was performed with dichloromethanemethanol mixtures: $99+1,98+2,97+3,95+5,9+1$ and $8+2$. Fraction $98+2$ contained a mixture of the compounds 1 and 2 which were purified by HPLC on RP8. Gradient elution with methanol-water yielded $1.12 \mathrm{mg} 1$ and $1.53 \mathrm{mg} 2$.

The ${ }^{1} \mathrm{H}$ and ${ }^{13} \mathrm{C}$ NMR data of 1 and 2 indicated a tropine structure. Their complete assignments were established by combining the information obtained by oneand two-dimensional NMR-techniques (COSY, HSQC, HMBC, selective TOCSYand NOE-experiments). The selective 1D-NOE experiments confirmed the relative 
configuration at the $\mathrm{C}_{2}$ bridge of 2 and allowed the assignment of the "endo" and "exo" protons: $\mathrm{H}-6_{\text {endo }}\left(\delta\right.$ 5.77), $\mathrm{H}-7_{\text {endo }}\left(\delta\right.$ 2.68), $\mathrm{H}-7_{\text {exo }}(\delta$ 2.20-2.27). The relative configuration of the 7-OH derivative 1 was determined by comparing its NOE's with recorded data of 2: $\mathrm{H}-6_{\text {endo }}(\delta 5.75), \mathrm{H}-7_{\text {endo }}(\delta 4.72)$.

On the basis of these spectral data, the structure of compound 2 was identified as catuabin C. Compound 1 was identified as 7-exo-hydroxy-20-methyl-catuabin C.

Separation of fraction $9+1$ by HPLC on RP8 showed two polar alkaloids (positive reaction with Dragendorff reagent on TLC) which were characterized by their molecular weights ( $3 \mathrm{~m} / \mathrm{z}=280,4 \mathrm{~m} / \mathrm{z}=264)$. The amounts were too small for NMR analyses but the fragments obtained by El-MS resembled to those of 1 and 2 indicating also alkaloids with a tropane structure (see experimental).

Fig. 1 Structural formulas of compounds 1 and 2

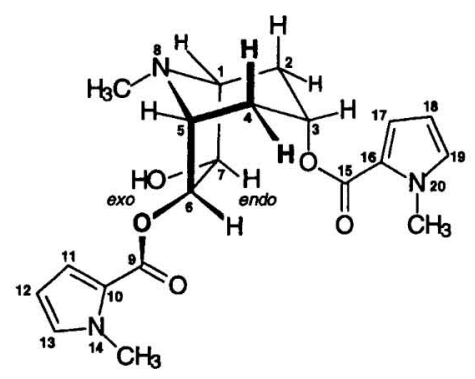

1

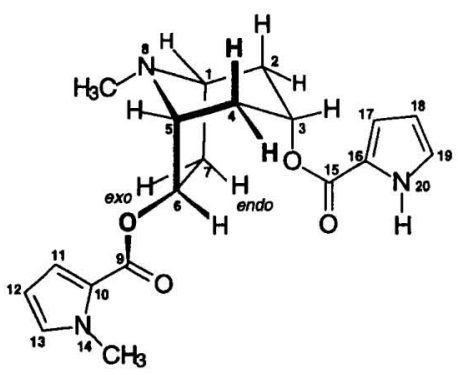

2

\section{Conclusion}

Tropane alkaloids are described for several families (Solanaceae, Erythroxylaceae, Proteaceae, Euphorbiaceae, Rhizophoraceae, Convolvulaceae, Cruciferae) [4]. Catuabin $C$ is known for Erythroxylum vacciniifolium [5,6] and the investigation of "Erythroxylum catuaba" showed similar alkaloids [7]. However, there is no evidence for this type of compounds in Bignoniaceae. The fact that tropane alkaloids were found in a sample specified as bark of Anemopaegma miran- 
dum (Bignoniaceae) indicates that, additionally, a species of the genus Erythroxylum is present. This corresponds to Daly [8] and Marques [9] who report that various genera are collected and traded under the name Catuaba. The resulting identification problems are subject of a paper in preparation.

\section{Acknowledgement}

The authors are grateful to S. Schlucker, M. Kaniak, W. Stindl, and J. Filipp for their engagement during the isolation work. The Brazilian company As Ervas Curam kindly supplied the drug free of charge.

\section{References}

[1] Schlucker S.

Untersuchungen zum Aphrodisiakum "Catuaba".

Master's thesis, University of Vienna 1998.

[2] Kaniak M.

Alkaloide, Gerbstoffe, Pflanzensäuren und Saccharide im Aphrodisiakum Catuaba.

Master's thesis, University of Vienna 1999.

[3] Stindl W.

Alkaloide aus dem Aphrodisiakum Catuaba.

Master's thesis, University of Vienna 2001.

[4] Griffin W J, Lin G D.

Chemotaxonomy and geographical distribution of tropane alkaloids.

Phytochemistry 2000; 53: 623-637.

[5] Graf E, Lude W.

Alkaloide aus Erythroxylum vacciniifolium MARTIUS, 1. Mitt. Isolierung von Catuabin A, B und C.

Arch Pharm (Weinheim) 1977; 310: 1005-1010.

[6] Graf E, Lude W.

Alkaloide aus Enythroxylum vacciniifolium MARTIUS, 2. Mitt. Strukturaufklärung von Catuabin $A, B$ und $C$.

Arch Pharm (Weinheim) 1978; 311: 139-152. 
[7] Zanolari B, Guilet D, Marston A, Queiroz E F, Paulo M Q, Hostettmann K. Tropane alkaloids from the bark of Erythroxylum catuaba (Erythroxylaceae). GA congress, Barcelona, Book of Abstracts, Revista de Fitoterapia 2002; 2 (Suppl 1): B223.

[8] Daly D.

The genus Tetragastris and the forests of eastern Brazil. Kew Bulletin 1990; 45: 179-194.

[9] Marques L C.

Contribuicao ao esclarecimento da identidade botanica da droga vegetal catuaba.

Espec de Capa 1998; Mar/Abr: 8-11. 